\title{
DIFFICULTY AND REASONS FOR SUSTAINABLE ROADWAY DESIGN - THE CASE FROM TAIWAN
}

\author{
Andrew S. CHANG, Calista Y. TSAI \\ Department of Civil Engineering, National Cheng Kung University, \\ No. 1 University Rd., Tainan, Taiwan
}

Received 29 Aug 2011; accepted 07 Aug 2012

\begin{abstract}
To accomplish sustainable design, it is essential to understand its barriers or limitations. This study investigated difficulties and their reasons for sustainable design using roadways as an example. A checklist of 60 sustainability items for roadway design was used to interview roadway designers to identify levels of difficulty, reasons for difficulty and proportions of difficulty reasons when designing these sustainability items. The results were analyzed and compared among sustainable items and design work.

The difficulties of incorporating sustainability into designs are classified into three levels as compared with conventional design: equal, medium and high. The average difficulty for sustainable roadway design is between low and medium level; 28 of the 60 items were found to be at the same level of difficulty as conventional design. The technical items are regarded more difficult to adopt than material items.

Nine reasons were identified for sustainable roadway design difficulty in which four are in the pre-design stage and five are in the design stage. The proportions of difficulty reasons in the pre-design and design stages are $63 \%$ and $37 \%$, respectively. This implies that more difficulties will be encountered in the pre-design stage, and the designers can try to overcome or reduce difficulty in design stage. The top three reasons are natural preconditions; criteria and specifications; and owner, policy and law, which cause $33 \%, 20 \%$ and $14 \%$ of the difficulty, respectively.

This study pointed out the difficulties and reasons for sustainable roadway design. Having a comprehensive understanding of the difficulties allows a designer to more accurately determine potential limitation, and to make better choices as to which sustainable items a particular construction project should pursue.
\end{abstract}

Keywords: sustainable design, roadway project, level of difficulty, difficulty reason.

\section{Introduction}

Sustainable development has become an important issue, but many construction engineers have little idea how to approach this emerging issue. Merritt (1998) surveyed UK companies and indicated their managers had little knowledge of how to manage their environmental performance, and employed few environmental practices. Chong et al. (2009) surveyed over 200 civil engineers in the US, and nearly all respondents regarded sustainability as important, but the actual application and implementation by their organizations was extremely low.

Engineering consultants provide planning and design services in the initial stages of the infrastructure life cycle. The energy and materials needed for, and waste produced by, infrastructure in the sequential stages of construction and operation has a great impact on the environment (McLellan et al. 2009). The impact made during the operation stage could be greatly reduced if sustainability is considered early in the planning and design stages.
Some guidelines provide sustainable requirements and practices for construction, but difficulties or barriers will be encountered when implementing them. LEED (Leadership in Energy and Environmental Design) is a green building evaluation system and an initiative for sustainability in the construction industry. It provides a project checklist of credits required to evaluate the environmental performance of a building (USGBC 2009). The AASHTO (American Association of State Highway and Transportation Officials) developed a compendium of practices, procedures, and policies for integrating environmental stewardship into highway construction and maintenance activities for the Departments of Transportation (DOT) in many states (TRB 2004). Shen et al. (2007) developed a checklist to understand the factors affecting a construction project's sustainability performance across its life cycle. These guidance documents need systematic methods or tools to facilitate implementation. 
Because sustainability is important especially to engineering designers whose work output will impact the environment greatly while they are not familiar with sustainable design, it is necessary to identify possible barriers to better manage them when incorporating sustainability into conventional design.

Therefore, the objective of this study was to identify difficulties and their reasons to avoid, reduce or overcome them for sustainable roadway design. The roadway is familiar to designers and is a type of conventional construction projects. The sustainable problems encountered during its design can be learned and managed by other types of construction projects.

\section{Literature review}

Different studies proposed barriers or difficulty reasons of implementing sustainable design as shown in Table 1. Dewberry (1996) surveyed green design or ecodesign practices in the UK and concluded that ecodesign was constrained by schedules, budgets, and design criteria. Risks of failure to incorporate sustainability into projects included lack of knowledge and experience, uncertainty of resources and techniques, cost, and few existing standard specifications (Ram, van Knippenberg 1998). van Hemel and Cramer (2002) performed an empirical study on the ecodesign behavior of 77 Dutch SMEs and found that the barriers to ecodesign included unclear environmental benefit, unsupported specifications or owners, limited budget and schedule, insufficient knowledge and experience, etc. Waage (2007) stated that the incorporation of sustainability concepts into design was constrained by product or service specifications, cost, schedule, available materials and techniques, market needs, and designer knowledge and experiences. Santolaria et al. (2011) found from innovation driven companies in Spain that the obstacles to the integration of environmental criteria into strategic plans were lack of tangible environmental benefits, lack of man- agement commitment, limited cost, legislation limitations, lack of experience, technical difficulties, etc.

More than 30 sustainable design casesf roadway projects in Japan were collected (Institute of Transportation 2004). In these cases, reasons for difficulty in sustainable roadway design included natural preconditions, insufficient data, specifications, constructability and maintainability, and interface coordination. Selih (2007) compiled a list of 11 potential obstacles for implementing environmental management system (EMS) in the construction industry such as expensive implementation cost, lack of technology and materials, and lack of governmental pressure. Lam et al. (2009) found 15 potential barriers to the integration of green specifications in construction. They were grouped into five categories including cost, time, technical issues, contractual considerations, and management matters. Management matters were related to owner commitments, inadequate experience, and available resources. Among these barriers, engineering consultants were particularly concerned with the additional costs of, and limited knowledge about, green technology and materials. Holton et al. (2010) investigated the UK precast concrete companies and found barriers to managing for sustainability including commitment of senior management or local ownership, knowledge and experience, and communication.

Tsai and Chang (2012) established a checklist of 60 roadway sustainability items as shown in Table 2 (the level of difficulty column is added from this study and will be explained in Section 2). The items were identified from studies and real projects first, and evaluated through ten interviews with 24 experienced practitioners including designers, owners, and contractors. The items are actually sustainable measures or methods that can be adopted to reduce environmental impact of construction projects (TRB 2004).

The 60 items include 15 material and 45 technique items categorized into 14 roadway disciplines. Each dis-

Table 1. Difficulty reasons for implementing sustainable design

\begin{tabular}{|c|c|c|c|c|c|c|c|c|c|}
\hline Studies & 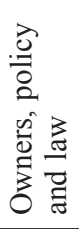 & 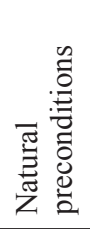 & $\begin{array}{l}\stackrel{0}{J} \\
\overrightarrow{0} \\
\frac{0}{0} \\
0 \\
0 \\
0 \\
000 \\
0 \\
0 \\
0\end{array}$ & 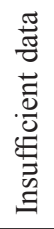 & 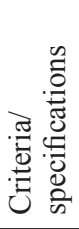 & 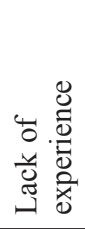 & 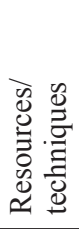 & 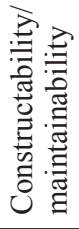 & 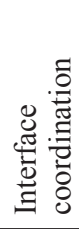 \\
\hline 1. Dewberry (1996) & & & $\checkmark$ & & $\checkmark$ & $\checkmark$ & & & \\
\hline 2. Ram and van Knippenberg (1998) & & & $\checkmark$ & & $\checkmark$ & $\checkmark$ & $\checkmark$ & & \\
\hline 3. van Hemel and Cramer (2002) & $\checkmark$ & & $\checkmark$ & $\checkmark$ & $\checkmark$ & $\checkmark$ & & & \\
\hline 4. Waage (2007) & $\checkmark$ & & $\checkmark$ & & $\checkmark$ & $\checkmark$ & $\checkmark$ & & \\
\hline 5. Santolaria et al. (2011) & $\checkmark$ & & $\checkmark$ & $\checkmark$ & $\checkmark$ & $\checkmark$ & $\checkmark$ & & \\
\hline 6. Institute of Transportation (2004) & & $\checkmark$ & & $\checkmark$ & $\checkmark$ & & & $\checkmark$ & $\checkmark$ \\
\hline 7. Selih (2007) & $\checkmark$ & & $\checkmark$ & & & & $\checkmark$ & & \\
\hline 8. Lam et al. (2009) & $\checkmark$ & & $\checkmark$ & & $\checkmark$ & $\checkmark$ & $\checkmark$ & & \\
\hline 9. Holton et al. (2010) & $\checkmark$ & & & & & $\checkmark$ & & & $\checkmark$ \\
\hline $\begin{array}{r}\text { Total } \\
\end{array}$ & 6 & 1 & 7 & 3 & 7 & 7 & 5 & 1 & 2 \\
\hline
\end{tabular}


cipline consists of various numbers of material and technique items and the material items are marked $(\mathrm{m})$ in Table 2. For example, the pavement discipline includes one technique item, reduction in volume or weight, and four other material items. These items had been individually defined.

Sustainability has three facets: economic, environmental, and social. This study only discusses environmental sustainability.

\section{Research methodology}

This study adopted the case study and focused group interview methods. A large engineering consulting firm was selected as the case company because it specializes in and has large portions of revenue from transportation projects and can be representative of roadway design practices in Taiwan. Twenty three designers of the company with over 20 years of roadway related experience were interviewed eight times to identify difficulty and reasons for implementing sustainable roadway design.

The research process is shown in the lower half of Figure 1. Following the prior work of Tsai and Chang (2012), this study used the checklist of the 60 items shown in Table 2 to interview roadway designers of the case company to determine levels of difficulty, reasons for difficulty and proportions of reasons when designing the 60 sustainability items. Because the designers know

Table 2. Sustainability roadway design items and their levels of difficulty

\begin{tabular}{|c|c|c|c|c|c|}
\hline 1. Geometrics \& Alignments & Level & 6. Slope Protection & Level & 10. Bridges & Level \\
\hline $\begin{array}{l}\text { 1) Reduction in volume or } \\
\text { weight }\end{array}$ & $\bullet$ & 1) Vegetation & - & $\begin{array}{l}\text { 1) Reduction in volume or } \\
\text { weight }\end{array}$ & $\bullet \bullet$ \\
\hline 2) Mild curves & - & 2) Reinforced slopes & - & 2) Long-span bridges & $\bullet \bullet$ \\
\hline 3) Mild slopes & - & 3) Waste reuse (m) & - & 3) Pre-casting techniques & $\bullet$ \\
\hline 2. Earthworks & & 7. Landscape \& Ecology & & $\begin{array}{l}\text { 4) Temporary bridges for } \\
\text { construction }\end{array}$ & $\bullet$ \\
\hline 1) Earthwork balance & $\bullet \bullet$ & $\begin{array}{l}\text { 1) Avoidance of natural } \\
\text { preservation sites }\end{array}$ & $\bullet \bullet$ & 5) Hollow railings & - \\
\hline $\begin{array}{l}\text { 2) Minimizing excavation } \\
\text { and fills }\end{array}$ & $\bullet \bullet$ & $\begin{array}{l}\text { 2) Replacement of } \\
\text { embankments or cuttings with } \\
\text { bridges or tunnels }\end{array}$ & $\bullet$ & 6) Reinforced materials (m) & - \\
\hline 3) Topsoil recycling & - & 3) Native trees & - & 7) High strength concrete (m) & - \\
\hline 4) Waste reuse (m) & - & 4) (Treasure) Tree transplanting & - & 8) Self-compacting concrete (m) & - \\
\hline 3. Pavement & & 5) Vegetation & - & 9) Lightweight concrete (m) & $\bullet$ \\
\hline $\begin{array}{l}\text { 1) Reduction in volume or } \\
\text { weight }\end{array}$ & $\bullet \bullet$ & 6) Topsoil recycling & - & 10) Steel (m) & - \\
\hline 2) Permeable materials (m) & - & $\begin{array}{l}\text { 7) Culverts for wildlife } \\
\text { crossings }\end{array}$ & $\bullet \bullet$ & 11. Sound Insulation & \\
\hline 3) Recycled materials (m) & - & 8) Ecological ponds & $\bullet$ & $\begin{array}{l}\text { 1) Reduction in volume or } \\
\text { weight }\end{array}$ & $\bullet \bullet$ \\
\hline $\begin{array}{l}\text { 4) Noise reduction materials } \\
\text { (m) }\end{array}$ & - & 9) Habitat connectivity & $\bullet \bullet$ & 2) Landscaping & - \\
\hline 5) Fiber materials (m) & $\bullet \bullet$ & $\begin{array}{l}\text { 10) Biologically porous } \\
\text { environment }\end{array}$ & $\bullet$ & 12. Tunnels & \\
\hline 4. Drainage & & $\begin{array}{l}\text { 11) Reduction in landscaping } \\
\text { facilities }\end{array}$ & - & $\begin{array}{l}\text { 1) Reduction in volume or } \\
\text { weight }\end{array}$ & $\bullet$ \\
\hline 1) Runoff reduction & $\bullet \bullet$ & 12) High bridges & - & 2) Vegetation & - \\
\hline 2) Vegetated or gravel ditches & $\bullet$ & 8. Transportation Facilities & & $\begin{array}{l}\text { 3) Reduction in ventilation } \\
\text { facilities }\end{array}$ & $\bullet$ \\
\hline 3) Rainwater catchments & $\bullet$ & $\begin{array}{l}\text { 1) Reduction in volume or } \\
\text { weight }\end{array}$ & $\bullet$ & 4) Waste reuse (m) & - \\
\hline $\begin{array}{l}\text { 4) Infiltration trenches or } \\
\text { catch basins }\end{array}$ & $\bullet$ & 2) Multi-function poles & $\bullet \bullet$ & 5) Fiber materials (m) & $\bullet \bullet$ \\
\hline 5) Sediment ponds & $\bullet$ & $\begin{array}{l}\text { 9. Transportation } \\
\text { Maintenance }\end{array}$ & & $\begin{array}{l}\text { 13. Electrical \& Mechanical } \\
\text { work }\end{array}$ & \\
\hline 6) Regional materials (m) & $\bullet$ & 1) Reduction in path changes & - & $\begin{array}{l}\text { 1) Reduction in transportation } \\
\text { controlling facilities }\end{array}$ & - \\
\hline 5. Retaining walls & & & & 14. Lighting & \\
\hline $\begin{array}{l}\text { 1) Reduction in volume or } \\
\text { weight }\end{array}$ & $\bullet$ & & & $\begin{array}{l}\text { 1) Reduction in lighting } \\
\text { facilities }\end{array}$ & $\bullet$ \\
\hline 2) Vegetation & - & & & 2) Renewable energy & $\bullet \bullet$ \\
\hline $\begin{array}{l}\text { 3) Grinding stones or soft } \\
\text { reinforcement }\end{array}$ & $\bullet$ & & & 3) Shading board (m) & - \\
\hline
\end{tabular}




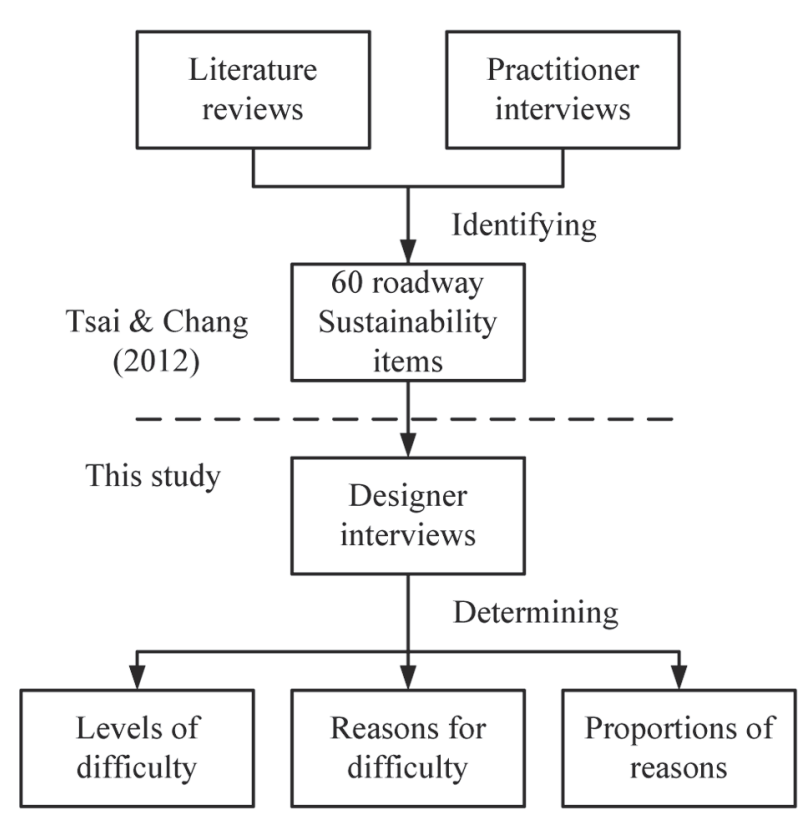

Fig. 1. Research process

design work better than the owners and contractors, the latter were not interviewed like that in the prior research process (Tsai, Chang 2012).

To investigate the difficulty of adopting these items, conventional design should be examined first. That is, the process of integrating sustainability items into design is linked and compared to the conventional design process (Waage 2007; Gagnon et al. 2012). Therefore, the roadway design work was collected and classified into 14 conventional design disciplines as shown in Table 2 after a review and analysis of planning and design quality management documents of the case company (Chang et al. 2008). Sustainability items then could be mapped during the design process and evaluated as to how they were incorporated into design.

Then a group of eight designers from the roadway department of the case company was interviewed. They were from different disciplines of roadway design work, such as pavement, drainage, bridges, etc. The 60 items were presented to them and explained and three levels of difficulty were offered for discussion and choice. The level of design difficulty was determined for each sustainable item during three interviews according to their experience with the items. The results are shown in the level of difficulty column in Table 2 .

Next, the reasons for difficulty when adopting the sustainable items were solicited. The designers' own reasons were inquired, or the barriers in the studies were mentioned to them for selection. The nine reasons were identified as shown in Table 1. Then, the major and minor reasons were indicated for items with high and medium difficulties. The proportions of difficulty reasons for items were calculated accordingly. The proportion calculations are explained in Sections 3.2 and 4.2.

Finally, the above results of the difficulty levels and reasons were examined for appropriateness in the next five interviews with another 15 designers (3 designers each) from five other departments. Their work was related to the 14 roadway disciplines such as drainage, electrical and mechanical design. The foregoing results were confirmed or modified during the five interviews.

Case studies are recognized as a suitable research method for exploratory studies such as this one, which has to describe and analyze the context of sustainability (Yin 2009). This method has been adopted in many sustainability studies (Palme, Tillman 2008; Holton et al. 2010; Borchardt et al. 2011). Focused interviews with designers are emphasized because designers have a better understanding of current design practices and the contextualization of sustainability items (Stewart et al. 2007; Yang et al. 2009).

Barriers of sustainable design have been studied by survey and empirical methods as mentioned in the literature review. In the survey method, the barriers are usually first collected from literature, listed in a questionnaire, sent to surveyees to pick, and then summarized (Selih 2007; Shen et al. 2007). But the backgrounds of the respondents and the reliability of their reply are not known. Furthermore, the sustainability issues and their context are not easy to separate in a survey method (Anderson, Muench 2010). This study adopted the empirical method especially the case study and interview that can supplement the survey method in presenting a clearer picture of the barriers.

The 60 sustainability items adopted to determine the difficulties and reasons are from the construction environment in Taiwan. It is possible that some items are not emphasized but other sustainability measures are relevant to projects in other countries. For example, the long bridges, emphasized in Taiwan in recent years to reduce the risk of erosion of bridge piers in a river, may not receive the same level of difficulty if assessed from other environments. In such a case, the levels of difficulty and reasons determined can be different. But the method of this study can be used for other environments to determine their own sets of difficulties and reasons.

\section{Results of difficulty of incorporating sustainability}

As compared to conventional roadway design, the levels of difficulty of incorporating the 60 sustainable items into design were assessed. Each item was assigned a level of difficulty. Some items such as reduction in weight and clean materials are frequently suggested but not necessarily the most successfully adopted (van Hemel, Cramer 2002). They could be achieved but require a great deal of effort from designers (Arditi et al. 2002). These efforts imply the levels of design difficulty (O'Connor, Miller 1995).

\subsection{Levels of difficulty}

The design difficulty for incorporating sustainability items is classified into three levels. As seen in Table 2, "-" represents equal- or low- level, “॰” represents medium-level, 


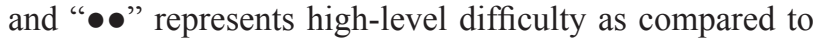
conventional design work. Design difficulties of medium or high level represent a certain amount of adoption difficulty. There are two criteria for design difficulty: the item itself is difficult to design; and the item becomes difficult to design because of limitations or interface cooperation (Dahlmann et al. 2008). For example, the item of avoidance of natural preservation sites in Landscape and Ecology (1st item in the 7th discipline in Table 2) was regarded as high difficulty because of data collection requirements. If related data can be acquired in the earlier stage, it is not difficult in the design to consider Avoidance of natural preservation sites.

The indicated difficulty levels of these sustainability items have to be understood in the context of the statements made by interviewees (Hartmuth et al. 2008). For example, items such as vegetated or gravel ditches in Drainage are difficult to be incorporated into design when the land is limited. Further, the same sustainable item may be regarded as having different levels of difficulty in different disciplines. For example, in Geometrics \& Alignments and Pavement, reduction in volume or weight was determined to have medium and high levels of difficulty, respectively. Reduction in volume or weight in Geometrics \& Alignments requires the reduction of the widths of traffic lanes. This is not difficult to achieve because of flexible design criteria. As for pavement, reduction in volume or weight requires reduction in the depths of pavement layers. This would be difficult to achieve because of rigid requirements for minimum pavement depths in the specifications.

\subsection{Difficulty analysis}

The difficulty values of the items are calculated based on the weights of three levels. The weights of levels of low, medium, and high were assumed to be 0,1 , and 2 points, respectively. The difficulty levels of the 14 roadway design disciplines, as well as their values, are calculated and summarized in Table 3. For example, Geometrics \& Alignments has two items of low difficulty and one item of medium difficulty as seen in Table 2; based on the assumed weights, their difficulty values are added to 1 point $(2 \times 0+1 \times 1+0 \times 2=1)$ and 0.3 points $(1 / 3)$ on average for three items, as seen in Table 3 .

Table 3 indicates that 28,18 , and 14 items are categorized to low, medium, and high levels with $47 \%, 30 \%$, and $23 \%$, respectively. Twenty eight or about half of the 60 items are classified as low difficulty. That is, they would not increase the difficulty of a design when adopted. The total of all difficulty values for the 60 items is 46 points and the average is 0.77 points. The average difficulty is between low ( 0 point) and medium (1 point) level. This value indicates that sustainable roadway design would increase certain difficulty compared to conventional design.

Of the 14 disciplines, Landscape \& Ecology and Bridges have the highest difficulty values, with 9 and 7 points, respectively. This is probably because Landscape \& Ecology and Bridge contain more items (12 and 10 in Table 2). Normalization can be applied to standardize the design difficulty of disciplines to prevent higher difficulty values caused by a greater number of items (IChemE 2003; Palme, Tillman 2008). Normalized difficulty is the quotient of the sum of the difficulty point divided by the number of total items. As seen in Table 3, Geometrics \& Alignments includes three items and its total difficulty was 1 point. So, its average difficulty value is 0.3 as shown in the right column.

Figure 2 vidually presents the average levels of difficulty of the 14 disciplines. Transportation Facilities has the highest average difficulty value: 1.5 . The average difficulties of Slope Protection, Transportaton Maintenance, and Electrical \& Mechanical Work are zero. Seven disci-

Table 3. Levels of difficulty of roadway design work

\begin{tabular}{|c|c|c|c|c|c|c|}
\hline $\begin{array}{l}\text { Levels of difficulty } \\
\text { Roadway design work }\end{array}$ & - & $\bullet$ & $\bullet \bullet$ & Total & Points & Average \\
\hline 1. Geometrics \& Alignments & 2 & 1 & 0 & 3 & 1 & 0.3 \\
\hline 2. Earthworks & 2 & 0 & 2 & 4 & 4 & 1.0 \\
\hline 3. Pavement & 3 & 0 & 2 & 5 & 4 & 0.8 \\
\hline 4. Drainage & 0 & 5 & 1 & 6 & 7 & 1.2 \\
\hline 5. Retaining Walls & 1 & 2 & 0 & 3 & 2 & 0.7 \\
\hline 6. Slope Protection & 3 & 0 & 0 & 3 & 0 & 0 \\
\hline 7. Landscape \& Ecology & 6 & 3 & 3 & 12 & 9 & 0.8 \\
\hline 8. Transportation Facilities & 0 & 1 & 1 & 2 & 3 & 1.5 \\
\hline 9. Transportation Maintenance & 1 & 0 & 0 & 1 & 0 & 0 \\
\hline 10. Bridges & 5 & 3 & 2 & 10 & 7 & 0.7 \\
\hline 11. Sound Insulation & 1 & 0 & 1 & 2 & 2 & 1.0 \\
\hline 12. Tunnels & 2 & 2 & 1 & 5 & 4 & 0.8 \\
\hline 13. Electrical \& Mechanical Work & 1 & 0 & 0 & 1 & 0 & 0 \\
\hline 14. Lighting & 1 & 1 & 1 & 3 & 3 & 1.0 \\
\hline Total $(\%)$ & $28(47)$ & $18(30)$ & $14(23)$ & 60 & 46 & 0.77 \\
\hline
\end{tabular}




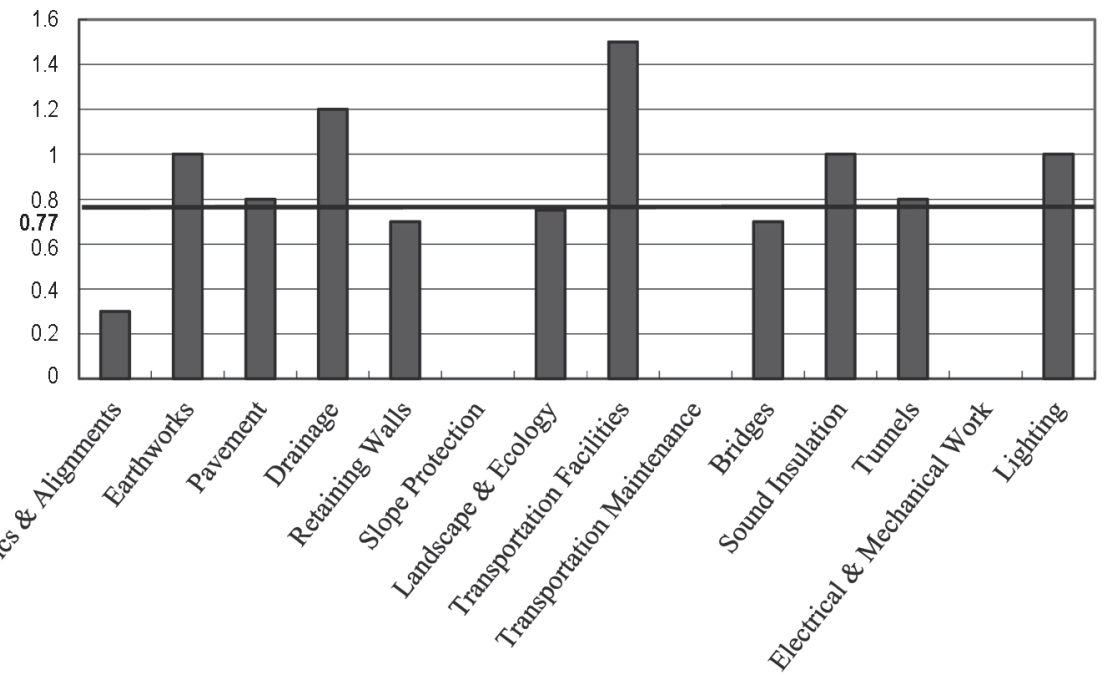

Fig. 2. Average difficulty of 14 design disciplines

plines including Earthworks, Pavement, Drainage, Transportation Facilities, Sound Insulation, Tunnels, and Lighting have a average value greater than 0.77 .

\subsection{Difficulty in materials and techniques}

The difficulty levels of materials and techniques are also examined as shown in Table 4. Most material items have low difficulty because they have been adopted in conventional design, such as high strength concrete and steel in Bridges. Seven disciplines such as Geometrics \& Alignments and Retaining Walls do not have sustainable material items. As summarized in Table 4, 11, 2 and 2 material items are categorized as low, medium, and high difficulty, respectively. Their difficulty values are 6 points in total and 0.40 points on average.
The design difficulty of techniques is higher than that of materials. As seen in Table 4, 17, 16, and 12 technique items are categorized as low, medium, and high difficulty, respectively. Their difficulty values are 40 points in total and 0.89 point on average. This is probably because sustainability is a new issue with few existing techniques. They are regarded more difficult to adopt in design than materials.

\section{Results of reasons for difficulty}

After the difficulty levels of the 60 sustainable items have been determined, the reasons for difficulties are identified and analyzed in this section.

The nine reasons in Table 1 were collected first after literature review and validated through designer in-

Table 4. Difficulty levels of materials and techniques

\begin{tabular}{|c|c|c|c|c|c|c|c|c|c|c|}
\hline \multirow{2}{*}{ Roadway Design Work } & \multicolumn{5}{|c|}{ Materials } & \multicolumn{5}{|c|}{ Techniques } \\
\hline & - & $\bullet$ & $\bullet \bullet$ & Total & Points & - & $\bullet$ & $\bullet \bullet$ & Total & Points \\
\hline 1. Geometrics \& Alignments & 0 & 0 & 0 & 0 & 0 & 2 & 1 & 0 & 3 & 1 \\
\hline 2. Earthworks & 1 & 0 & 0 & 1 & 0 & 1 & 0 & 2 & 6 & 4 \\
\hline 3. Pavement & 3 & 0 & 1 & 4 & 2 & 0 & 0 & 1 & 1 & 2 \\
\hline 4. Drainage & 0 & 1 & 0 & 1 & 1 & 0 & 4 & 1 & 5 & 6 \\
\hline 5. Retaining Walls & 0 & 0 & 0 & 0 & 0 & 1 & 2 & 0 & 3 & 2 \\
\hline 6. Slope Protection & 1 & 0 & 0 & 1 & 0 & 2 & 0 & 0 & 2 & 0 \\
\hline 7. Landscape \& Ecology & 0 & 0 & 0 & 0 & 0 & 6 & 3 & 3 & 12 & 9 \\
\hline 8. Transportation Facilities & 0 & 0 & 0 & 0 & 0 & 0 & 1 & 1 & 5 & 3 \\
\hline 9. Transportation Maintenance & 0 & 0 & 0 & 0 & 0 & 1 & 0 & 0 & 1 & 0 \\
\hline 10. Bridges & 4 & 1 & 0 & 5 & 1 & 1 & 2 & 2 & 5 & 6 \\
\hline 11. Sound Insulation & 0 & 0 & 0 & 0 & 0 & 1 & 0 & 1 & 2 & 2 \\
\hline 12. Tunnels & 1 & 0 & 1 & 2 & 2 & 1 & 2 & 0 & 3 & 2 \\
\hline 13. Electrical \& Mechanical Work & 0 & 0 & 0 & 0 & 0 & 1 & 0 & 0 & 1 & 0 \\
\hline 14. Lighting & 1 & 0 & 0 & 1 & 0 & 0 & 1 & 1 & 2 & 3 \\
\hline Total & 11 & 2 & 2 & 15 & 6 & 17 & 16 & 12 & 45 & 40 \\
\hline Average & \multicolumn{5}{|c|}{$0.40(6 / 15)$} & \multicolumn{5}{|c|}{$0.89(40 / 45)$} \\
\hline
\end{tabular}


terviews in this study. Among the nine reasons, Budget/ schedule, Criteria/specifications and Lack of experience are most frequently mentioned (7 times) and followed by Owner, policy and law (6 times) and Resources/techniques (5 times).

\subsection{Definitions of nine reasons}

The definitions of the nine reasons in Table 1 and their limitations for roadway design are described as follows. The first four reasons occur before the design starts and the rest five reasons occur during design.

1. Owner, policy and law. The owner's requirements, government policy and law affect designers' sustainability consideration in the first place. The owner is a key factor limiting sustainable design. The adoption of sustainability in design is positively related to the degree of owner support (Ball 2002). Policies and laws are governed by the government. Sustainable design will not be implemented successfully without incentives from policies and laws (Holton et al. 2010; Massoud et al. 2010).

2. Natural preconditions. Sustainable design can be limited by natural preconditions including terrain, location, weather, available land, etc. For example, ventilation shafts in tunnels are limited by the terrain and the location of a project.

3. Budget and schedule. Cost and schedule are major barriers to sustainable design (Radujković et al. 2010; Meryman, Silman 2004; Ofori, Kien 2004; Dewberry 1996). This can also be seen in Table 1 . For example, renewable energy may not be adopted in a lighting design because of the limited budget or schedule of a project.

4. Insufficient data. Some sustainability items need additional or long-term data to make design feasible. Insufficient data acquired in the design stage limits sustainable design. For example, the Culverts for wildlife crossings design in Landscape \& Ecology needs additional ecological survey data. Insufficient data in survey or literature would limit their adoption.

5. Criteria and specifications. Design practices are implemented in accordance with design criteria; and sustainability items will be difficult to design without design criteria. Besides, designers have to evaluate circumstances from all aspects when establishing specifications. For example, fiber materials are rarely adopted in roadways; a specification requiring fiber materials in pavement will limit its design.

6. Lack of experience. Limited experience or knowledge of sustainable materials or techniques can be an important barrier to sustainability incorporation (Lam et al. 2009; Berge, Henley 2000). For example, the implementation of long-span bridges may be difficult because of lack of design experience.

7. Resources and techniques. Availability of resources or techniques such as patents or tools may be neces- sary for sustainable design. Traditional suppliers may not be capable of providing sustainable resources or techniques (Pearce, Vanegas 2002). For example, Grinding stones or soft reinforcement in Retaining Walls may be constrained by lack of stones and technical labor, or because of patents on techniques.

8. Constructability and maintainability. Design has to consider constructability and maintainability in the subsequent stages. Constructability and maintainability reviews are valuable that must take place in the design phase (Arditi et al. 2002; Zimmerman, Hart 1982; Burati et al. 1992). For example, permeable materials in pavement would lose their function without careful maintenance; so they should not be adopted in pavement design if such future maintenance is not available.

9. Interface coordination. Design activities need coordination with and cooperation of practitioners including the design team and stakeholders such as material suppliers, constructors, the public, etc. Design difficulties can be resulted from frequent interface coordination (Holton et al. 2010). For example, adoption of multi-function poles in a transportation facility needs lots of coordination with landscape designers, electricians, and mechanics.

\subsection{Major and minor reasons at discipline levels}

It is necessary to understand the occurrence frequencies of the nine difficulty reasons. In Table 3, 32 items are regarded as medium (18) or high (14) difficulty. Their major and minor reasons and proportions are calculated in Table 5. The 28 low difficulty items do not increase difficulty when adopted in design so their reasons are not discussed.

As shown in Table 5, different proportions of difficulty reasons exist for different disciplines. Major and minor reasons for the 32 items in the 14 design disciplines are identified with weights given by interviewees. If design difficulty of an item is derived from a single reason, it is weighted 1.0 such as the Sound Insulation (11); if two reasons are involved, they are weighted as 0.8 and 0.2 such as Lighting (14) with reasons 2 and 7 to differentiate between the major and minor reasons (Junnila, Horvath 2003); three reasons are weighted as $0.5,0.3$, and 0.2 such as those in Geometrics \& Alignments (1). It is assumed that a sustainable item has a maximum of three difficulty reasons to avoid obscurity due to too many reasons.

As seen in Table 5, proportions of difficulty reasons in the pre-design and design stages are $63 \%$ and $37 \%$, respectively. That is, more difficulties will be encountered before design starts than during design for sustainable roadway design. The Natural preconditions has the highest value of $33 \%$ and limits the design of seven disciplines including Earthworks, Drainage, etc. Roadways are located in open space so their natural preconditions such as terrain, location, and available land area directly affect design considerations. Although natural preconditions is 
Table 5. Weights of difficulty reasons for sustainable roadway design

\begin{tabular}{|c|c|c|c|c|c|c|c|c|c|c|}
\hline \multirow{2}{*}{$\begin{array}{l}\text { Reasons for difficulty } \\
\text { Roadway Design Work }\end{array}$} & \multirow{2}{*}{$\begin{array}{l}\text { Difficult } \\
\text { item no. }\end{array}$} & \multicolumn{4}{|c|}{ Pre-design } & \multicolumn{5}{|c|}{ Design } \\
\hline & & 1 & 2 & 3 & 4 & 5 & 6 & 7 & 8 & 9 \\
\hline 1. Geometrics \& Alignments & 1 & 0.2 & & & & 0.5 & & & & 0.3 \\
\hline 2. Earthworks & 2 & & 1.6 & & & & & & & 0.4 \\
\hline 3. Pavement & 2 & & & & & 1.8 & 0.2 & & & \\
\hline 4. Drainage & 6 & 1.5 & 3.2 & & & 0.4 & 0.2 & & 0.7 & \\
\hline 5. Retaining Walls & 2 & 0.5 & 1.0 & & & 0.3 & & 0.2 & & \\
\hline 6. Slope Protection & 0 & & & & & & & & & \\
\hline 7. Landscape \& Ecology & 6 & & 1.0 & & 4.0 & & 1.0 & & & \\
\hline 8. Transportation Facilities & 2 & & 1.6 & & & & & & & 0.4 \\
\hline 9. Transportation Maintenance & 0 & & & & & & & & & \\
\hline 10. Bridges & 5 & 1.3 & 1.2 & & 0.2 & 0.7 & 0.8 & & & 0.8 \\
\hline 11. Sound Insulation & 1 & 1.0 & & & & & & & & \\
\hline 12. Tunnels & 3 & & & & & 2.8 & 0.2 & & & \\
\hline 13. Electrical \& Mechanical Work & 0 & & & & & & & & & \\
\hline 14. Lighting & 2 & & 0.8 & 1.0 & & & & 0.2 & & \\
\hline Total & 32 & 4.5 & 10.4 & 1.0 & 4.2 & 6.4 & 2.4 & 0.4 & 0.7 & 1.9 \\
\hline \multirow{2}{*}{ Percentage } & \multirow{2}{*}{100} & 14 & 33 & 3 & 13 & 20 & 8 & 1 & 2 & 6 \\
\hline & & \multicolumn{4}{|c|}{63} & \multicolumn{5}{|c|}{37} \\
\hline
\end{tabular}

not a frequent reason in Table 1 from studies, it is the major difficulty reason for sustainable roadway design. This difficulty of natural preconditions can be eliminated or reduced by selecting appropriate job site in the project feasibility or planning stage.

In Table 5, Criteria and specifications (reason 5) is the secondary limitation with $20 \%$, and affects six design disciplines such as Geometrics \& Alignments, Pavement, etc. Probably because sustainability is an emerging issue, conventional roadway criteria and specifications have not been adjusted to facilitate sustainable design. This difficulty can be reduced by designers to establish sustainable criteria and specifications.

Figure 3 visually shows the proportions of the nine reasons from the percentage row in Table 5. The subjec- tive reasons of lack of experience and interface coordination which can be influenced by designers take $8 \%$ and $6 \%$, respectively. These percentages would decrease when sustainable materials and techniques are getting mature and known to the construction project participants.

\subsection{Major and minor reasons at detailed item levels}

Reasons causing difficulty in the detailed design items can be analyzed using Drainage and Bridge as examples. As seen in the upper part of Table 6, Drainage work consists of six detailed sustainable items including Runoff reduction, Vegetated or gravel ditches, etc. Approximately $78 \%$ of the difficulty of sustainable drainage design exists before the design. As shown in Table 6 and Figure 4, five reasons limit sustainable drainage design including

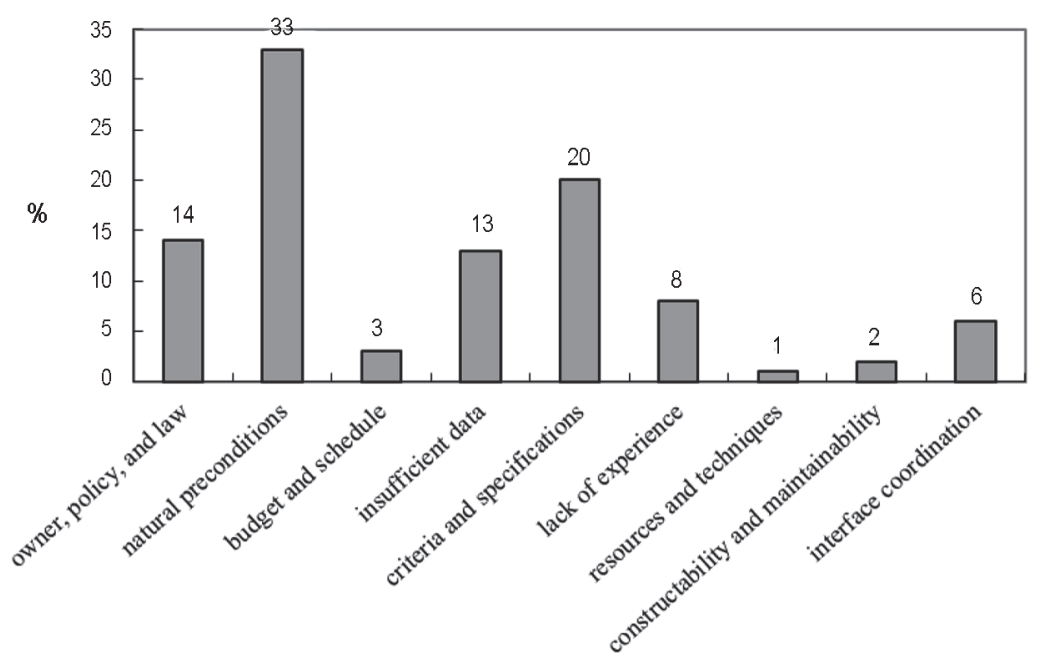

Fig. 3. Proportions of difficulty reasons in sustainable roadway design 
Table 6. Difficulty reasons in detailed drainage and bridge design

\begin{tabular}{|c|c|c|c|c|c|c|c|c|c|c|}
\hline \multirow{2}{*}{ Detailed sustainable items } & \multirow{2}{*}{$\begin{array}{l}\text { Difficulty } \\
\text { levels }\end{array}$} & \multicolumn{4}{|c|}{ Pre-design } & \multicolumn{5}{|c|}{ Design } \\
\hline & & 1 & 2 & 3 & 4 & 5 & 6 & 7 & 8 & 9 \\
\hline \multicolumn{11}{|l|}{ 4. Drainage } \\
\hline 1) Runoff reduction & $\bullet \bullet$ & 0.5 & 0.3 & & & 0.2 & & & & \\
\hline 2) Vegetated or gravel ditches & $\bullet$ & & 0.8 & & & & & & 0.2 & \\
\hline 3) Rainwater catchments & $\bullet$ & & 0.8 & & & & & & 0.2 & \\
\hline 4) Infiltration trenches or catch basins & $\bullet$ & & 0.5 & & & & 0.2 & & 0.3 & \\
\hline 5) Sediment ponds & $\bullet$ & & 0.8 & & & 0.2 & & & & \\
\hline 6) Regional materials (m) & $\bullet$ & 1.0 & & & & & & & & \\
\hline Total & 6 & 1.5 & 3.2 & 0 & 0 & 0.4 & 0.2 & 0 & 0.7 & 0 \\
\hline \multirow{2}{*}{ Percentage $(\%)$} & \multirow{2}{*}{100} & 25 & 53 & 0 & 0 & 7 & 3 & 0 & 12 & 0 \\
\hline & & \multicolumn{4}{|c|}{78} & \multicolumn{5}{|c|}{22} \\
\hline \multicolumn{11}{|l|}{ 10. Bridges } \\
\hline 1) Reduction in volume or weight & $\bullet \bullet$ & 0.8 & & & & 0.2 & & & & \\
\hline 2) Long-span bridges & $\bullet \bullet$ & & & & & 0.2 & 0.8 & & & \\
\hline 3) Pre-casting techniques & $\bullet$ & & 0.2 & & & & & & & 0.8 \\
\hline 4) Temporary bridges for construction & $\bullet$ & & 1.0 & & & & & & & \\
\hline 5) Lightweight concrete $(\mathrm{m})$ & $\bullet$ & 0.5 & & & 0.2 & 0.3 & & & & \\
\hline Total & 5 & 1.3 & 1.2 & 0 & 0.2 & 0.7 & 0.8 & 0 & 0 & 0.8 \\
\hline \multirow{2}{*}{ Percentage $(\%)$} & \multirow{2}{*}{100} & 26 & 24 & 0 & 4 & 14 & 16 & 0 & 0 & 16 \\
\hline & & \multicolumn{4}{|c|}{54} & \multicolumn{5}{|c|}{46} \\
\hline
\end{tabular}

Owner, policy and law (1); Natural preconditions (2); Criteria and specifications (5); Lack of experience (6); and Constructability and maintainability (8). Of these reasons, Natural preconditions is the major design limitation with a total weight of $53 \%$, and Owner, policy and law is the secondary limitation with $25 \%$. Over $50 \%$ of the difficulty arises from natural preconditions. This indicates that natural preconditions such as terrain, location, and available land determine sustainable drainage design.

Reasons causing difficulty in the detailed design items can be analyzed using Drainage and Bridge as examples. As seen in the upper part of Table 6, Drainage work consists of six detailed items (from Table 2) including Runoff reduction, Vegetated or gravel ditches, etc. Approximately $78 \%$ of the difficulty of sustainable drainage design exists before the design.
Figure 4 visually shows the proportions of the nine reasons from the two percentage rows for Drainage and Bridges in Table 6. As shown in Table 6 and Figure 4, the five reasons limiting sustainable drainage design are Owner, policy and law (1); Natural preconditions (2); Criteria and specifications (5); Lack of experience (6); and Constructability and maintainability (8). Of these reasons, Natural preconditions is the major design limitation with a total weight of $53 \%$, and Owner, policy and law is the secondary limitation with $25 \%$. Over $50 \%$ of the difficulty arises from natural preconditions. This indicates that natural preconditions such as terrain, location, and available land is a determining factor of sustainable design for drainage.

Table 6 also shows the reasons for detailed items in Drainage design. For example, Runoff reduction is limited

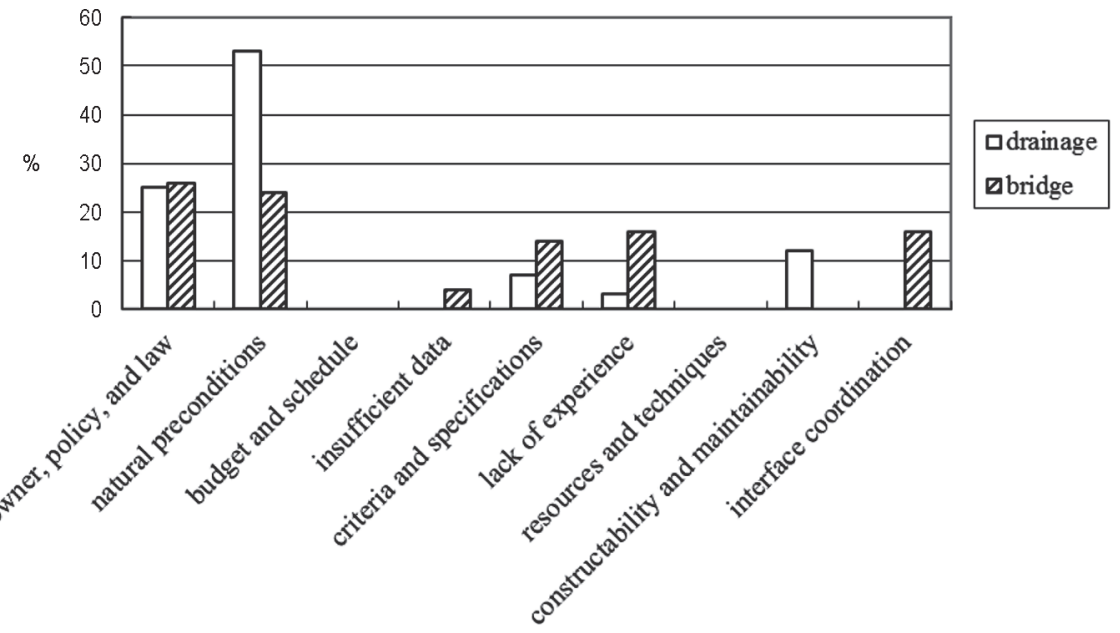

Fig. 4. Proportions of difficulty reasons in sustainable drainage and bridge design 
by three reasons including Owner, policy and law; Natural preconditions; and Criteria and specifications, with weights of $0.5,0.3$, and 0.2 , respectively. Owner, policy and law is the major barrier to design adoption. This is because runoff reduction usually has to be decided before the design is started. Land use planning and policies directly affect design alternatives. Vegetated or gravel ditches is limited by Natural preconditions and Constructability and maintainability with weights of 0.8 and 0.2 , respectively. That is, available land is the major limitation for designing the ditches; they would lose function for poor maintenance at the operation stage.

In addition, Table 6 and Figure 4 also show the difficulty reasons for Bridges. As shown in the lower part of Table 6, Bridge work consists of five sustainable items including Reduction in volume or weight, Long-span bridges, etc. Different disciplines have different proportions of difficulty reasons. Compared with Drainage, only $54 \%$ of the difficulty of sustainable bridge design exists before the design is started. Difficulties in the pre-design stage have a larger impact than those $(46 \%)$ in the design stage. It would be easier to reduce some difficulty before sustainable design for bridges than for drainage.

As seen in Figure 4, six difficulty reasons limiting sustainable bridge design are owner, policy and law; natural preconditions; insufficient data; criteria and specifications; lack of experience; and interface coordination. Among these reasons, owner, policy and law is the major limitation with a percentage of $26 \%$; natural preconditions is the secondary limitation with $24 \%$; and lack of experience and interface coordination are the tertiary limitation with $16 \%$ each.

The difficulty reasons for detailed sustainable items in bridge design are also indicated in Table 6. For example, Long-span bridges is limited by Criteria and specifications and Lack of experience with weights of 0.2 and 0.8 , respectively. Lack of experience is the major barrier to its design adoption. Long-span bridges have been recommended for design by owners in recent years, but the designer's experience is insufficient and relevant criteria and specifications need to be established.

Lightweight concrete is limited by Owner, policy and law; Insufficient data; and Criteria and specifications, with weights of $0.5,0.2$, and 0.3 , respectively. Lightweight concrete is a new sustainable material using recycled organo-modified reservoir sludge. There is a lack of sufficient data to prove its performance, so owners tend to reject its adoption on projects.

\section{Discussions}

The sustainable items have been proposed for roadway design in Section 1. The levels of difficulty of these items have been assessed in Section 3 and their difficulty reasons have been explained in Section 4. It would be more meaningful to practitioners if the difficulties can be overcome or reduced and the reasons can be avoided.

A roadway construction project can benefit from a standardized process early during the project design for adopting the most suitable sustainable items. Performing preliminary difficulty level review of these items can help ensure that the maximum number of items for environmental performance is obtained at the minimum level of difficulty. For instance, sustainable items with high-level difficulty should be carefully examined to verify that they could be overcome or reduced.

In the green building process, a project can decide which credit to pursue and which strategies to employee to obtain sufficient points to meet the LEED standards. This process is complex and involves many factors such as cost, schedule, technical feasibility, etc. (SBW consulting 2003). These factors are the difficulty reasons that will be faced and considered when pursuing sustainable roadway projects.

Different difficulty reasons will also be encountered by different industries, construction projects, and project components as analyzed in Section 4. For example, the proportions of the nine reasons presented in Figure 3 are different from their frequencies appearing in Table 1. National preconditions can be the major difficulty reason for sustainable roadway design but it is not a frequent barrier in Table 1 from studies of other sectors and projects; Budget and schedule is a minor reason for the roadway projects but it is raised by many studies. At the component level, Drainage and Bridges disciplines have different proportions of the nine reasons as seen in Figure 4. All these imply that sustainable design of different projects has to examine their own barriers and patterns in order to manage them.

The characteristics of the nine difficulty reasons are summarized in Table 7. The reasons are arranged in the order of occurrence in the design. The former four reasons exist in the pre-design stage, and the latter five exist during design execution. Designers have to overcome these difficulties to implement sustainable design from beginning to end. For example, designers have to evaluate whether criteria and specifications have limitations (reason 5), and

Table 7. Characteristics of difficulty reasons

\begin{tabular}{c|c|c|c|c|c|c|c|c|c}
\hline \multirow{2}{*}{ Characteristics } & \multicolumn{4}{|c|}{ Pre-design } & \multicolumn{5}{c}{ During design } \\
\cline { 2 - 11 } & 1 & 2 & 3 & 4 & 5 & 6 & 7 & 8 & 9 \\
\hline Subjective & $\checkmark$ & & $\checkmark$ & & & $\checkmark$ & & $\checkmark$ \\
\hline Objective & $\checkmark$ & $\checkmark$ & $\checkmark$ & $\checkmark$ & $\checkmark$ & & $\checkmark$ & $\checkmark$ & $\checkmark$ \\
\hline
\end{tabular}


assess whether their experience is sufficient (6). It will be more difficult for the designers to eliminate limitations in the pre-design stage than those in the design stage.

Moreover, nine reasons are categorized as subjective and objective. Subjective reasons include owner, policy and law (1), budget and schedule (3), lack of experience (6), and interface coordination (9). Objective reasons consist of all except lack of experience (6). The reasons of 1,3 , and 9 are both subjective and objective. Of the four subjective reasons, 1 and 3 are mainly governed by owners and are not easily changed by designers, but reasons 6 and 9 can be overcome by designers.

In summary, this study pointed out the difficulties and reasons for sustainable roadway design. Designers could perceive them before considering these items and evaluate ways to incorporate them into design.

\section{Conclusions}

This study investigated levels of difficulty and difficulty reasons for incorporating sustainable design items for roadway projects. A checklist of 60 sustainability roadway design items established by a previous study was used to interview designers to indicate levels of difficulty and difficulty reasons when adopting these items. Furthermore, the proportions of the difficulty reasons were also calculated.

The difficulties in incorporating sustainability into design are classified into three levels as compared with conventional work: equal, medium and high. The average level indicates that sustainable roadway design would increase certain difficulty; but 28 of the 60 items were evaluated as being at the same level of difficulty as conventional design. Design difficulty was found to have nine reasons; the former four reasons exist in the pre-design stage, and the latter five exist in the design stage. In general, the reasons in the pre-design stage cause more difficulty than those during design. Natural preconditions is the major limitation for roadway sustainable design.

As we can see, the difficulty reasons have a significant impact on the ability to achieve specific sustainable items so limit sustainable design. When considering the feasibility for pursuing sustainable design, it is extremely important that the designer understands the feasibility of each sustainable item for the project, and the difficulty and reasons affecting its feasibility.

One limitation of this research is that the difficulty levels and reasons determined out of this study may not be the same for other construction projects or environments. For example, budget and schedule is only a minor reason from this study but it is raised by many studies. The other limitation is that the difficulty levels and reasons were collected only from the designers of the construction profession. But the viewpoints may be different from owners, contractors, or other stakeholders. These imply that sustainable design of different projects has to examine their own barriers and perspectives in order to manage them.
This study only investigated design difficulties and their reasons. Future research could identify the difficulties and reasons for incorporating sustainability at subsequent stages, such as construction and operation, to ensure that adopted design items are practical to implement in the project life cycle. It is worth investigating ways to overcome these difficulties during execution in the design stage or in earlier stages of feasibility study or planning.

Although this study used roadway design as an example, the method for identifying the difficulties and their reasons can be used on other types of construction projects. Future research may collect related sustainable items based on the project types, and analyze their design difficulties and reasons to compare the similarity and difference in sustainability design among different construction projects.

\section{Acknowledgement}

The authors would like to thank CECI engineering consultants Inc. for arranging interviews with its designers.

\section{References}

Anderson, J.; Muench, S. 2010. Greenroads manual v1.0. University of Washington, Seattle.

Arditi, D.; Elhassan, A.; Toklu, Y. C. 2002. Constructability analysis in the design firm, Journal of Construction Engineering and Management ASCE 128(2): 117-126.

http://dx.doi.org/10.1061/(ASCE)0733-9364(2002)128:2(117)

Ball, J. 2002. Can ISO 14000 and ecolabeling turn the construction industry green?, Building Environment 37: 421-428. http://dx.doi.org/10.1016/S0360-1323(01)00031-2

Berge, B.; Henley, F. 2000. The ecology of building materials. Boston: Architectural Press.

Borchardt, M.; Wendt, M. H.; Pereira, G. M.; Sellitto, M. A. 2011. Redesign of component based on ecodesign practices: environmental impact and cost reduction achievements, Journal of Cleaner Production 19: 49-57. http://dx.doi.org/10.1016/j.jclepro.2010.08.006

Burati, J. L. Jr.; Farrington, J. J.; Ledbetter, W. B. 1992. Causes of quality deviations in design and construction, Journal of Construction Engineering and Management ASCE 118(2): 34-49.

http://dx.doi.org/10.1061/(ASCE)0733-9364(1992)118:1(34)

Chang, A. S.; Shih, J. S.; Chen, S. Y. 2008. First time correctness ratio: a quality measure applied to design work. Research Report 97604, CECI (in Chinese).

Chong, W. K.; Kumar, S.; Haas, C. T.; Beheiry, S. M. A.; Coplen, L.; Oey, M. 2009. Understanding and interpreting baseline perceptions of sustainability in construction among civil engineers in the United States, Journal of Management in Engineering ASCE 25(3): 143-154.

http://dx.doi.org/10.1061/(ASCE)0742-597X(2009)25:3(143)

Dahlmann, F.; Brammer, S.; Millington, A. 2008. Barriers to proactive environmental management in the U.K.: implications for business and public policy, Journal of General Management 33(3): 1-20.

Dewberry, E. 1996. Ecodesign - present attitudes and future directions: studies of UK company and design consultancy practice. PhD Thesis. Technology Faculty, Open University.

Gagnon, B.; Leduc, R.; Savard, L. 2012. From a conventional to a sustainable engineering design process: different shades of sustainability, Journal of Engineering Design 23(1): 49-74. http://dx.doi.org/10.1080/09544828.2010.516246 
Hartmuth, G.; Huber, K.; Rink, D. 2008. Operationalization and contextualization of sustainability at the local level, Sustainable Development 16: 261-270. http://dx.doi.org/10.1002/sd.377

Holton, I.; Glass, J.; Price, A. D. F. 2010. Managing for sustainability: findings from four company case studies in the UK precast concrete industry, Journal of Cleaner Production 18: 152-160. http://dx.doi.org/10.1016/j.jclepro.2009.09.016

Institute of Transportation. 2004. The research report for establishing specifications in planning and designing sustainable roads. MOTC, Taipei, Taiwan (in Chinese).

Institution of Chemical Engineers (IChemE). 2003. The sustainability metrics: sustainable development process metrics recommended for the use in process industries. Institution of Chemical Engineers, Rugby, UK.

Junnila, S.; Horvath, A. 2003. Life-cycle environmental effects of an office building, Journal of Infrastructure Systems ASCE 9(4): 157-166.

http://dx.doi.org/10.1061/(ASCE)1076-0342(2003)9:4(157)

Lam, P. T. I.; Chan, E. H. W.; Chau, C. K.; Poon, C. S.; Chun, K. P. 2009. Integrating green specifications in construction and overcoming barriers in their use, Journal of Professional Issues in Engineering Education and Practice ASCE 135(4): 142-152.

http://dx.doi.org/10.1061/(ASCE)1052-3928(2009)135:4(142)

Massoud, M. A.; Fayad, R.; El-Fadel, M.; Kamleh, R. 2010. Drivers, barriers and incentives to implementing environmental management systems in the food industry: a case of Lebanon, Journal of Cleaner Production 18: 200-209. http://dx.doi.org/10.1016/j.jclepro.2009.09.022

McLellan, B. C.; Corder, G. D.; Giurco, D.; Green, S. 2009. Incorporating sustainable development in the design of mineral processing operations - review and analysis of current approaches, Journal of Cleaner Production 17: 1414-1425. http://dx.doi.org/10.1016/j.jclepro.2009.06.003

Merritt, J. 1998. EM into SME won't go? Attitudes, awareness and practices in the london borough of croydon, Business Strategy Environment 7: 90-100. http://dx.doi.org/10.1002/(SICI) 1099-0836(199805)7:2<90::AID-BSE141>3.0.CO;2-F

Meryman, H.; Silman, R. 2004. Sustainable engineering - using specifications to make it happen, Structural Engineering International 14(3): 216-219. http://dx.doi.org/10.2749/101686604777963856

O’Connor, M.; Miller, S. J. 1995. Overcoming barriers to successful constructability implementation efforts, Journal of Performance of Constructed Facilities 9(2): 117-128. http://dx.doi.org/10.1061/(ASCE)0887-3828(1995)9:2(117)

Ofori, G.; Kien, H. L. 2004. Translating Singapore architects' environmental awareness into decision making, Building Research and Information 32(1): 27-37. http://dx.doi.org/10.1080/09613210210132928

Palme, U.; Tillman, A. M. 2008. Sustainable development indicators: how are they used in Swedish water utilities?, Journal of Cleaner Production 16: 1346-1357. http://dx.doi.org/10.1016/j.jclepro.2007.07.001

Pearce, A. R.; Vanegas, J. A. 2002. A parametric review of the built environment sustainability literature, International Journal of Environmental Technology and Management 2(1-3): 54-93.

http://dx.doi.org/10.1504/IJETM.2002.000779
Radujković, M.; Vukomanović, M.; Dunović, I. B. 2010. Application of key performance indicators in south-eastern european construction, Journal of Civil Engineering and Management 16(4): 521-530. http://dx.doi.org/10.3846/jcem.2010.58

Ram, B.; van Knippenberg, P. 1998. Ecodesign workshop. Philips CEEO \& Philips CFT.

Santolaria, M.; Oliver-Solà, J.; Gasol, C. M.; Morales-Pinzón, T.; Rieradevall, J. 2011. Eco-design in innovation driven companies: perception, predictions and the main drivers of integration. The Spanish example, Journal of Cleaner Production 19: 1315-1323.

http://dx.doi.org/10.1016/j.jclepro.2011.03.009

SBW consulting, Inc. 2003. Achieving silver LEED: preliminary benefit-cost analysis for two City of Seattle facilities. Final report submitted to Seattle Office of Sustainability and Environment, Seattle, Washington.

Selih, J. 2007. Environmental management systems and construction SMES: A case study for Slovenia, Journal of Civil Engineering and Management 13(3): 217-226.

Shen, L. Y.; Hao, J. L.; Tam, V. W.; Yao, H. 2007. A checklist for assessing sustainability performance of construction projects, Journal of Civil Engineering and Management 13(4): 273-281.

Stewart, D. W.; Shamdasani, P. N.; Rook, D. W. 2007. Focus groups: theory and practice. $2^{\text {nd }}$ ed. Applied social research methods series. Thousand Oaks, CA: Sage Publications.

Transportation Research Board (TRB). 2004. Environmental stewardship practices, procedures, and policies for highway construction and maintenance. National Cooperative Highway Research Program, NCHRP Report 25-25(04). Venner Consulting and Parsons Brinckerhoff.

Tsai, C. Y.; Chang, A. S. 2012. Framework for developing construction sustainability items: the example of highway design, Journal of Cleaner Production 20: 127-136. http://dx.doi.org/10.1016/j.jclepro.2011.08.009

United States Green Building Council (USGBC). 2009. LEED for new construction and major renovations. Version 3.0, April. Green Building Council, Washington, DC.

van Hemel, C.; Cramer, J. 2002. Barriers and stimuli for ecodesign in SMEs, Journal of Cleaner Production 10: 439-453. http://dx.doi.org/10.1016/S0959-6526(02)00013-6

Waage, S. A. 2007. Re-considering product design: a practical "road-map" for integration of sustainability issues, Journal of Cleaner Production 15: 638-649.

http://dx.doi.org/10.1016/j.jclepro.2005.11.026

Yang, J.; Shen, G. Q.; Ho, M.; Drew, D. S.; Chan, A. P. C. 2009. Exploring critical success factors for stakeholder management in construction projects, Journal of Civil Engineering and Management 15(4): 337-348.

http://dx.doi.org/10.3846/1392-3730.2009.15.337-348

Yin, R. K. 2009. Case study research: design and methods. $4^{\text {th }}$ ed. Applied social research methods series. Thousand Oaks, CA: Sage Publications

Zimmerman, L. W.; Hart, G. D. 1982. Value engineering - a practical approach for owners, designers, and contractors. New York: Van Nostrand Reinhold.

Andrew S. CHANG. Andrew S. Chang is a professor of Civil Engineering Department of National Cheng Kung University in Taiwan. He has over 20 years of project control experience on large engineering and construction projects. He received a $\mathrm{PhD}$ from the University of California at Berkeley, and is a registered professional engineer in California.

Calista Y. TSAI. Calista Y. Tsai is a PhD graduated from Civil Engineering Department of National Cheng Kung University in Taiwan. She has 10 years of construction management and project scheduling. Her PhD thesis concerns incorporating sustainability into construction design practices. 